\title{
A Methodology to Measure the Degree of Managerial Innovation
}

\author{
Mustafa Batuhan Ayhan, Ercan Oztemel \\ Marmara University Faculty of Engineering Industrial Engineering Department (Turkey) \\ batuban.ayban@marmara.edu.tr, eoztemel@marmara.edu.tr
}

Received: September 2013

Accepted: January 2014

\section{Abstract:}

Purpose: The main objective of this study is to introduce the concept of managerial innovation and to propose a quantitative methodology to measure the degree of managerial innovation capability by analyzing the evolution of the techniques used for management functions.

Design/methodology/approach: The methodology mainly focuses on the different techniques used for each management functions namely; Planning, Organizing, Leading, Controlling and Coordinating. These functions are studied and the different techniques used for them are listed. Since the techniques used for these management functions evolve in time due to technological and social changes, a methodology is required to measure the degree of managerial innovation capability. This competency is measured through an analysis performed to point out which techniques used for each of these functions.

Findings: To check the validity and applicability of this methodology, it is implemented to a manufacturing company. Depending on the results of the implementation, enhancements are suggested to the company for each function to survive in the changing managerial conditions

Research limitations/implications: The primary limitation of this study is the implementation area. Although the study is implemented in just a single manufacturing company, it is welcomed to apply the same methodology to measure the managerial innovation capabilities of other manufacturing companies. Moreover, the model is ready to be adapted to different sectors although it is mainly prepared for manufacturing sector. 
Originality/value: Although innovation management is widely studied, managerial innovation is a new concept and introduced to measure the capability to challenge the changes occur in managerial functions. As a brief this methodology aims to be a pioneer in the field of managerial innovation regarding the evolution of management functions. Therefore it is expected to lead more studies to inspect the progress of change throughout the history and the future trends.

Keywords: management functions, innovation, managerial change, degree of managerial innovation

\section{Introduction}

Management idea is studied over several decades by various researchers. However, in the era of industrial revolution, it was set on a scientific base by the studies of Frederick Taylor, which was originally published in 1911 (Taylor, 2010). Although many of the management scientists still have been developing new management models, studies about evaluating the success rate to follow the most contemporary ones are limited yet. To fulfill this gap in the literature, this study aims to analyze the evolution of management science and moreover, depending on this progress, a methodology to measure the degree of managerial innovation is elaborated.

Before analyzing the evolution of management science, the concept should be clarified as well as explaining its functions. "Management" is defined as the coordination and direction of the activities of oneself and others for the aim of particular objectives (Witzel, 2004). In order to achieve the organizational goals, 4 important functions of management are defined in literature; Planning, Organizing, Leading, and Controlling (Daft, 2008). In addition Coordination of the staff has been becoming an important issue to deal with.

In addition, "Management Innovation" can be defined as; the invention and implementation of a management practice, process, structure, or technique that is new to the state of the art and is intended to further organizational goals (Birkinshaw, Hamel \& Mol, 2008). Based on this definition, the sources of management innovation and the association with firm performance are studied in the literature (Mol \& Birkinshaw, 2009). Besides, "Innovation Management" is also studied widely in the literature, which focuses on the management of the innovation process. However, the "Managerial Innovation", which is introduced as a new concept, can be defined as the capability to handle the changes occurring in the management functions, in the most appropriate way. Therefore, to measure this capability degree, the evolution of management and the changes occur in managerial functions should be analyzed at first.

The evolution of management idea can be shown as in Figure 1. It starts with "Scientific Management Theory" with the pioneer researches of Frederick Taylor (1856-1915) about 
division of labor (Taylor, 2010) as well as Frank and Lillian Gilbreths' (1868-1924; 1878-1972) researches about Time and Motion studies (Witzel, 2005). In the second step, the "Administrative Management Theory" (Jones \& George, 2010) is defined according to "Theory of Bureaucracy" developed by Max Weber (1864-1920) including 4 principles to form a system of organization (Cole \& Kelly, 2011) and 14 principles of management developed by Henri Fayol (1841-1925) (Smit et al., 2007). In the third step of the evolution, "Behavioral Management Theory" is proposed by the advocates Mary Parker Follet stating that Taylor ignored the human side of the organizations as well as providing the Hawthorne studies (Wren \& Bedeian, 2009) finding that a manager's behavior approach can affect workers' level of performance. In the same era, according to two assumptions proposed by Douglas McGregor; work attitudes and behaviors dominate the way managers think and affect how they behave in organizations (Witzel, 2005). As a brief, Theory $X$ assumes the average worker is lazy, dislikes work, and will try to do as little as possible, whereas, Theory $Y$ assumes, workers are not inherently lazy and if given the opportunity they will do what is good for the organization. According to $4^{\text {th }}$ phase of the evolution of "Management Science Theory", which is an approach to management that uses rigorous quantitative techniques to help managers, includes Quantitative Techniques (linear, nonlinear programming, simulation, etc.), Operations Management (Chase \& Prentis, 1987), Total Quality Management, and Management Information Systems (Smit et al., 2007). The "Organizational Environment Theory", concerns the set of forces and conditions that operate beyond an organization's boundaries but affect a manager's ability to acquire and utilize resources, including open and closed system view (Jones \& George, 2010).

\section{Organizational Environment Theory}

Management Science Theory

\section{Behavioral Management Theory}

Administrative Management Theory

Scientific Management Theory

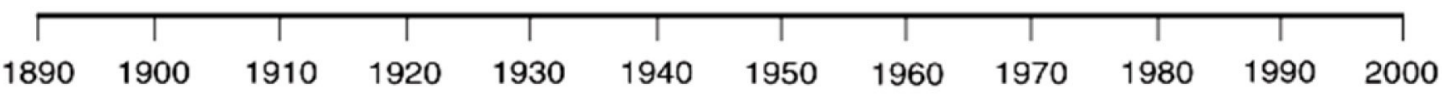

Figure 1. Evolution of Management Science (Smit, Cronje, Brevis \& Vrba, 2007) 
Furthermore, the evolution of management science can also be represented in different approaches in the literature (Robbins \& Coulter, 2009; Roth, 1994; Wren \& Bedeian, 2009; Johnson \& Breckon, 2006).

However, this progress in management is generally studied as an organizational point of view and manufacturing systems are less emphasized. Although the industrial revolution triggers the transformation of management concept from one phase to another, the properties possessed by the manufacturing systems are discarded. That is, the logic has changed to "scientific management"; however, the changes occurring in the functions of management are not elucidated. Therefore, this study is aimed to investigate these changes occur in the management functions-focusing on the manufacturing systems-parallel with the evolution of management science.

Moreover, to the best knowledge of the authors, there is a lack of methodology to analyze the success of the manufacturing companies about following the innovations in managerial functions. Hence, after explaining the changes occur in the functions of management for the manufacturing systems in the second part, a methodology is presented to measure the success rate of following the changes in these managerial functions and its validity is released in section three. Since calculating the degree of managerial innovation in a manufacturing system is the main motivation of this study the methodology is applied on a manufacturing company. By stating the results and discussions at the fourth part, further steps of this study are suggested at the end.

\section{Evolution of Managerial Functions}

Before explaining the managerial functions (Planning, Leading, Controlling, Organizing, and Coordinating) and their evolution, the transformation of the management science should be depicted focusing on a manufacturing perspective. This progress starts from the pre-scientific era representing the period before the industrial revolution and to the post modern techniques used for virtual management.

In the "Pre-scientific" era, number of product types and variety was little. Since there existed only a small shop and the owner of the shop could work as both the manager and the worker of the shop, management could be handled by the owner of the production facility as explained in original version published in 1911 (Taylor, 2007). However by the industrial revolution, productivity, product portfolio, number of customers significantly increased. Departmentalization is also required to manage the organizations in a "Functional Based" approach. Therefore scientific techniques are required to follow the changes in managerial functions for the manufacturing systems. In the beginning of $20^{\text {th }}$ century, the importance of human relations and their interactions have been understood; hence the organizations set 
team working style. Teams, which consist of friendly working employees, have some projects and aims to be accomplished. Therefore the "Process Management" concept releases and the changes in managerial functions should be pursued regarding manufacturing systems (Thompson, 1995). In the middle of $20^{\text {th }}$ century "Management By Objectives", which was introduced by Peter Drucker in his book "The Practice of Management" (Drucker, 2007), is a process of agreeing upon objectives within an organization so that management and employees agree to the objectives and understand what they are in the organization. It uses some mathematical models to set the objectives and measure the success rate by introducing the SMART criteria (Specific, Measurable, Achievable, Relevant, and Time-Specific) to management concept. Since Peter Drucker sets new milestones in the field of modern management, the Druckerian perspective is studied to enlighten the management style of future trends (Wallman, 2010).

In the new era of the post modern approach, with the developments of new technologies and utilizing from the internet, management concept is revolving to another facet. Virtual Management is about managing people at a distance using technology and companies are suggested to define their structure according to this new virtual organization style (Introna \& Petrakaki, 2007). It seeks to separate certain responsibilities of managers from the actual site of production, the workers and resources at that site. It means maintaining close working relationships with colleagues in many locations, without the need for as many meetings as traditionally required. In virtual management, not only the managers can lead and control the employees virtually, but also the employees generally called virtual teams can plan, organize, and communicate the required issues to perform the responsible tasks locating in different parts. Home office approach is one of the new trends implementing virtual management techniques. However, the vital importance of new communication techniques usually internet, tele-conferencing should not be discarded in this management type. Depending on the new improvements of technology, management functions totally mutate based on computerized intranet and internet technologies (By, Burnes \& Oswick, 2011).

As a brief, the evolution of the techniques used for managerial functions can be entitled depending on these 5 stages and shown in Figure 2. In the following sections, each of these functions; Planning, Organizing, Leading, Controlling, and Coordinating will be elucidated and the transformation of the methods used for these functions is explained. 


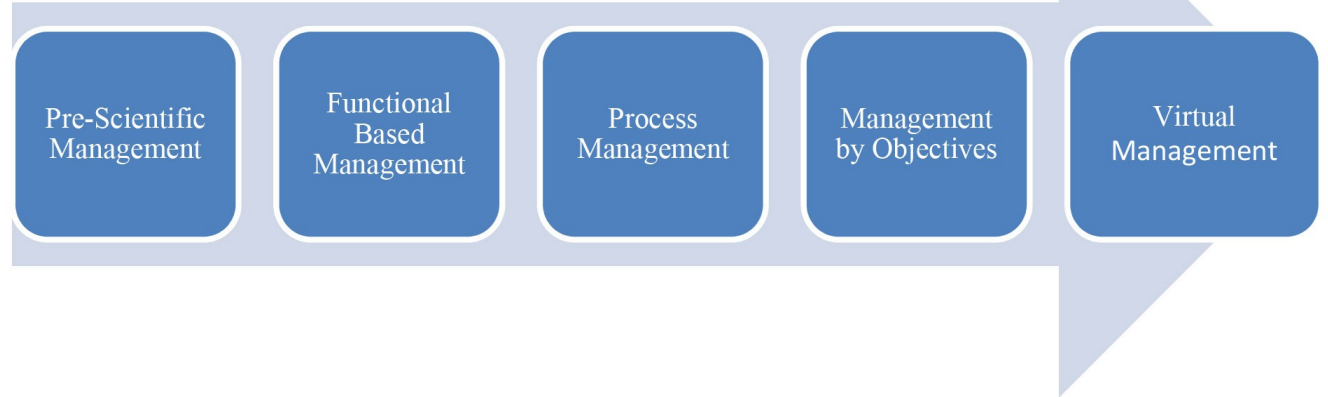

Figure 2. Evolution of Managerial Functions

\subsection{Planning}

Planning is defining goals for future organizational performance and deciding on the tasks and use of resources needed to attain those (Daft, 2008). Although different types of planning methodologies exist, this study aims to analyze the historical evolution of the methods used for planning function with respect to the changes occur in manufacturing systems. Therefore, from the simplest method to the most contemporary one, this evolution can be listed as follows.

- Rules: In the "Pre-Scientific" era, since the manufacturing capacity and types of products are limited (Wren \& Bedeian, 2009), only the set of "Rules", which are stated by the manager, are adequate to plan the manufacturing. This set includes a list of "Do's" and "Do Not's" to perform the planning function of basic manufacturing systems.

- Procedures: They are a series of related steps to be followed in an established order to achieve a given purpose. Depending on the industrial revolution, the product types and quantity have increased tremendously. To overcome the problems each step of each task should be well defined. Since procedures prescribe exactly what actions are to be taken in a specific situation and are necessary for each department, they are the distinctive technique to be used in the "Functional Based" management style. Although implementing Procedures is uppermost important for this period, the application of "Rules" as the planning techniques still remains.

- Processes: Planning by processes, which is developed accompanying with the "Process Management" idea, asserts that the planning activities should be performed by the process owners of each task (Benner \& Tushman, 2003). Although, "Rules", and "Procedures" are preceding techniques for planning, they are still necessary for each department and operation. However they are not enough for the planning function. Since the employees are grouped as teams and each team have different tasks, 
planning with "Processes" can be stated as the distinctive technique of Planning Function and requires more importance to deal with.

- Programs: Arising with the "Management by Objectives" idea, "Programs" emerged to be a distinctive technique for planning function as they are typically intended to accomplish a specific objective within a fixed time to set the overall objective of the company (Drucker, 1993). It is clear that preceding techniques are still to be used, but the importance of using Programs for planning is higher than the previous ones.

- Rolling Plans: The post modern "Virtual Management" approach, delineates the requirement of "Rolling Plans" rather than static ones, in order to keep up with the changes occur in the competitive market and even for different geographical and cultural changes. As it is expected, the importance of this technique is higher than the previous ones, although they are still in use.

Hence, in order to follow the changes in managerial functions, stated 5 planning techniques should be in use. Definitely the most contemporary ones have more importance in usage for planning rather than the previous ones.

\subsection{Organizing}

Organizing is the process of assigning the tasks to employees, determining the hierarchical levels, and responsibilities and the authorities of each staff regarding the entrepreneurial objectives (Daft, 2008). Since the manufacturing organizations are living entities, they evolve in time due to developing technologies and the areas of organizational changes are studied by Griffin (2010). However every company can require different types of organizational schemes regarding with the changes occur in manufacturing processes. In addition in some cases cross functional organizational structure may be required (Ford \& Randolph, 1992). Some of the main theories and approaches to organizational changes are reviewed in the literature (Armenakis \& Bedeian, 1999; By, 2005).

- Product Based: It is the organizational scheme of "Pre-Scientific" management era. Since, there exist only a few products, the main focus of the organization is to produce that products. It classifies the resources according to the product(s) being manufactured, as shown in Figure 3. 


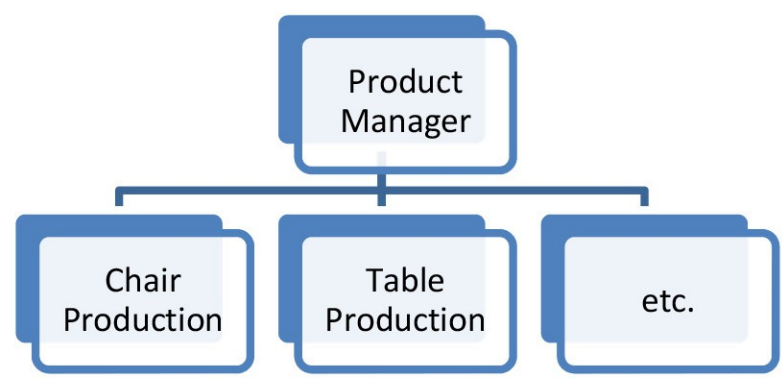

Figure 3. Product based organizational scheme

- Department Based: It is the organizational scheme of "Departmental" management era. Since, the numbers of products and types increase, departments are required for the organization. It departments the resources and the employees due to tasks occur and shown in Figure 4.

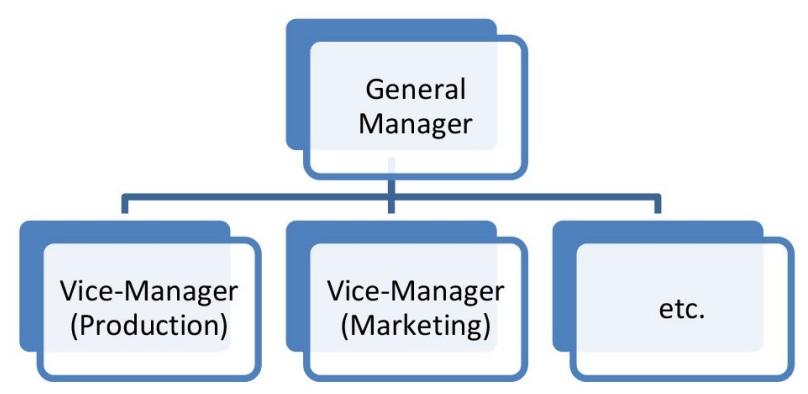

Figure 4. Department based organizational scheme

- Process Based: It is the organizational scheme of "Process Management" era. Since, the processes are in the core interest, the resources and the employees are structured according to these manufacturing processes as shown in Figure 5.

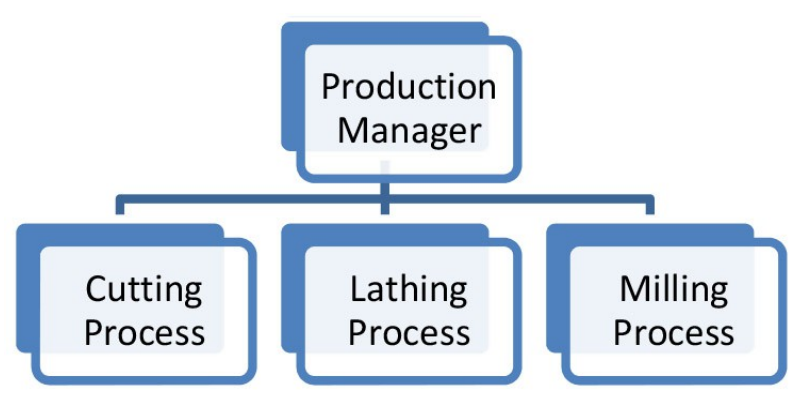

Figure 5. Process based organizational scheme 
- Customer Based: It is the organizational scheme of "Management by Objectives" era. Since, the main objective is to meet the customer demands in a rapid way, the resources and the employees are structured according to customer requirements as shown in Figure 6.

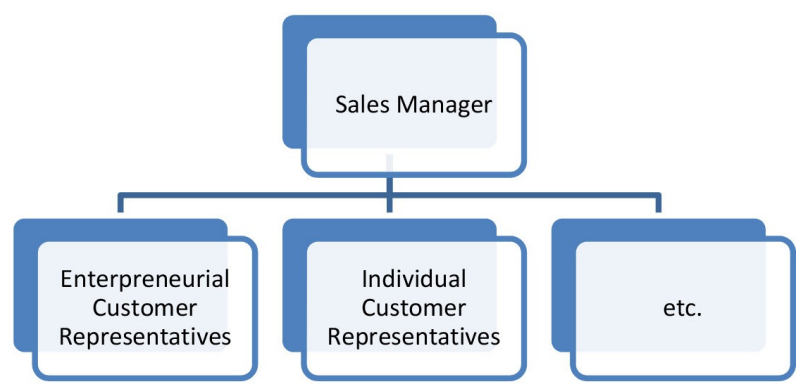

Figure 6. Customer based organizational scheme

- Territory Based: It is the organizational scheme of "Virtual Management" era. Since the manufacturing companies compete in a global market, it is vital important to set their structure in different areas as shown in Figure 7.

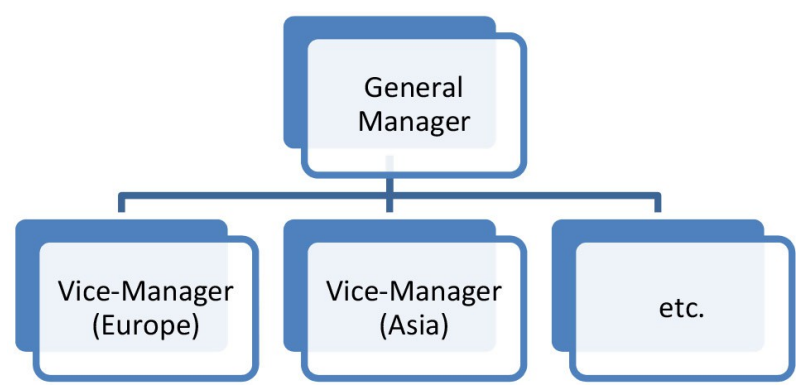

Figure 7. Territory based organizational scheme

Hence, in order to follow the changes in managerial functions, stated 5 organizational schemes should be in use co-operatively. Definitely the latter ones have more importance in usage for organizing; regarding the changes occur rather than the formers.

\subsection{Leading}

It is the art of influencing the individuals or group activities to achieve the company's objectives (Daft, 2008). There are various studies about leading and motivating the employees 
in the literature, however the leadership behavior changes in 5 phases accompanying with the progress of management regarding the manufacturing systems (for more detail; Daft, 2008; Drucker, 2007; Murray, 2010).

- Dictative Leadership: It is the style of "Pre-Scientific" management era. Since the leader is most probably the owner of the company, leader dictates what is expected from the workers.

- Structural Leadership: It is the style of "Departmental" management era. Leader shares the authority with department leaders.

- Supportive Leadership: It is the style of "Process Management" era. Since the leader is also a part of a process, leader is contributive to the employees' problems.

- Participatory Leadership: It is the style of "Management by Objectives" era. Leader sets the objectives of the company by consulting the subordinates; otherwise it is hard to accomplish the objectives successfully.

- Esteemed Leadership: It is the style of "Virtual Management" era. Depending on the globalization structure of the international market, the leader should be self-esteemed and respectful with his behavioral style. Subordinates will definitely identify, respect and follow to a prestigious and well-known leader.

In order to follow the changes in managerial functions, the leader should behave all of the above styles successfully. Definitely the latter ones have more importance in usage for organizing regarding the changes occur rather than the formers.

\subsection{Controlling}

Organizational control is defined as the systematic process through which managers regulate organizational activities to make them consistent with the expectations established in plans, targets, and performance standards (Daft, 2008). Briefly, controlling is making something happen the way it was planned to happen. Since the manufacturing technologies evolve in time, controlling mechanisms also transforms from the primitive case to the most contemporary techniques. Existing controlling methods can be viewed (Daft, 2008; Drucker, 2007) and analyzed in this perspective.

- Control if Required: It is the technique of "Pre-Scientific" management era. Since the limited number of products, the controlling activity is adequate in case of a necessity. 
- Scheduled Control: It is the technique of "Departmental" management era. Since there are various departments responsible for different tasks, a pre-determined schedule period and frequency for the controlling activity is required.

- Flexible Control: It is the method of "Process Management". Since the tasks are organized in different ways of processes, each of them requires distinct techniques, which can be handled by a flexible controlling system.

- Continuous \& Self Control: In order to achieve the aims set by the "Management by Objectives" philosophy, every employee should control his or her responsibility in a continuous approach.

- Aggregated Control: For the post modern approach "Virtual Management", controlling mechanism should be achieved from anywhere and by anyone who has the authority. This can only be achieved by application of integrated computer systems and some ERP (Enterprise Resource Planning) programs

In order to follow the changes in managerial functions, controlling system should be ready to control in case of a necessity as well as for the implementation of a scheduled control. In addition, it should be flexible to keep up with the changing conditions, and in a continuous way to be controlled by each employee individually. As the last, an aggregated control system has the most importance regarding the global market structure. Hence controlling mechanism should embrace all of the mentioned techniques.

\subsection{Coordinating}

Although the literature signifies four managerial functions (Robbins, De Cenzo \& Coulter, 2010), only through the successful use of communication skills, departments can be coordinated well enough to enhance the attainment of management objectives. Therefore some communication styles are investigated to manage the coordinating function in the most proper way (Gomez-Mejia \& Balkin, 2011; Hitt, Black \& Porter, 2011). Since the changes occur in manufacturing systems, communication styles also advance from the primitive case to the most contemporary ones.

- Direct Communication: In the "Pre-Scientific Management" era, since a limited number of workers, a direct communication of the managers with the workers is required and adequate.

- Hierarchical Communication: In the "Departmental Management" era, it is the way of communication of the managers with the department leaders, and then the leaders informing the workers. 
- MIS (Management Information System): Since in the "Process Management" era, there are various processes and each of them uses different resources and assigned to many workers, communication becomes a tough task. Hence MIS should aid for the coordination of the workers and the manager (Gupta, 1992).

- Internet: In the "Management by Objectives" era, the aims set by the management, should be transmitted to all partners including the suppliers and the customers. Hence the usage of internet technologies is unavoidable and vital importance in this sense.

- Artificial Intelligence (AI) Communication: In the "Virtual Management" era, coordination cannot be dependent on the persons. For instance, an AI based system should autonomously inform the related supplier in case of an out-of-stock for a particular raw material minimizing the risk of misinformation caused by the employees.

In order to follow the changes in managerial functions, coordination of the organization should be well handled by the communication methods explained above. As expected the latter ones are more important than the former ones regarding the changes occur in manufacturing systems.

\subsection{Managerial Innovation}

The scope of this study is to measure the capability to follow the changes in management activities of manufacturing systems. These management functions are deeply investigated and the evolution of manufacturing management depending on the changes in managerial functions is analyzed. In order to measure the degree of managerial innovation, each function is investigated separately and relative weights are assigned according to the up to dateness of the method. From the primitive techniques to the post modern techniques, each one takes the importance weight of $2^{k}$, where $k$ takes the value of " 0 " for the primitive methods, and takes the value of " 4 " for the most contemporary one. Therefore, it is adequate to find out which method(s) are used for each function and to compute the relative weights of corresponding ones in order to calculate the degree of managerial innovation. The evolution of management science and the managerial functions with respect to manufacturing perspective is summarized in Table 1, as well as listing the assigned relative weights for each of the methods.

The reason to assign $\left(2^{k}\right)$ relative weight is simple. Through this approach, the most contemporary technique takes the highest weight. Then by summing up the relative weights of each technique, for each function, degree of managerial innovation can be calculated. For instance, if the manufacturing company utilized only the "Rules" and "Procedures", it will gather 3 points for the planning function. Hereby, one of the other reasons of assigning $2^{k}$ relative weights arises. That is, 3 points cannot be summed up except implementing the first 
and second techniques in practice. Therefore, when the total score for each function is known, it leads to definite deduction of which techniques used.

\begin{tabular}{|l|c|c|c|c|c|}
\hline $\begin{array}{c}\text { Manufacturing } \\
\text { Management } \\
\text { Types }\end{array}$ & Planning & Organizing & Leading & Controlling & Coordinating \\
\hline $\begin{array}{l}\text { Pre-Scientific } \\
\text { Management }\end{array}$ & Rules & Product & Dictative & If Required & Direct \\
\hline $\begin{array}{l}\text { Departmental } \\
\text { Management }\end{array}$ & Procedures & Departmental & Hierarchical & Scheduled & Hierarchical \\
\hline Process & $(2)$ & $(2)$ & $(1)$ & $(2)$ & $(2)$ \\
Management & Processes (4) & Process & Supportive & Flexible & MIS \\
\hline $\begin{array}{l}\text { Management } \\
\text { By Objectives }\end{array}$ & Programs & Customer & Participatory & Continuous \& Self & Internet \\
\hline Virtual & $(8)$ & $(8)$ & $(8)$ & $(8)$ & $(8)$ \\
Management & Rolling Plans (16) & Territory & Esteemed & Aggregated & AI \\
\hline
\end{tabular}

Table 1. Specific Management Functions with respective weights for each Manufacturing Management Type

Another important issue to be explained about Table 1; is the additive structure of each specific method for each function. For example, to be assumed as the "Departmental Management" era, although the "Procedures" technique is distinctive for this era, "Rules" technique should also be used. Therefore, in order to follow the contemporary changes in the management science regarding the manufacturing perspective, all of the techniques should be employed.

In the next section this methodology is studied for a manufacturing company to analyze in which managerial phase it is and to calculate the degree of managerial change with this respect.

\section{Validity of the Methodology}

The proposed methodology is utilized to measure capability of success to follow the changes occur in the management functions of a manufacturing company, which produces flex and pipes. By performing a survey with the general manager of the company, interviewing with the sub-ordinates, and observing the production line; application of these functions are investigated. Due to these observations to find out which technique(s) are performed for each of the management function, the application of the model is elucidated in next sections. 


\subsection{Innovation in Planning Function}

Through the analysis to find out which technique(s) are used among the pre-mentioned ones, "Rules", "Procedures", and "Processes" are revealed to be fully implemented for the planning function. However, "Programs" are performed with 50\% efficiency, depending on the fact that, there is a list of objectives set by the "Management by Objectives" philosophy; this list cannot be embedded to the planning function in a proper way. Moreover, it is hard to mention about the existence of "Rolling Plans", which is a planning technique of "Virtual Management" era. Therefore, by summing up the related scores taken from the fully implemented techniques ( 1 , 2 , and 4) and adding the half of the score of "Programs" method (4), the company aggregates 11 points. When this score is divided by the maximum score (31), which corresponds to the application of all planning methods, the capability to follow the changes in managerial function is found as $35.48 \%$ in Equation 1.

$$
P F=\left(\frac{11}{31}\right)=35.48 \%
$$

\subsection{Innovation in Organizing Function}

It is observed that, there are two main production areas to produces flex and pipes indicating a "Product Based" organization scheme. In addition there are also Marketing \& Sales, Finance \& Accounting departments pointing a "Departmental Based" organization scheme. However, there is not an indicator of a process based organization, because although there are two milling work centers operating in both of the production areas, nobody is responsible for the 'milling process', except the workers assigned on the machines. Furthermore there is no evidence of customer based organization and a territorial structure at all. Since the organizational structure is based on "Product" and "Departments", which are the most basic ones, the company aggregates 1 and 2 points for the related techniques and making up 3 points over the maximum available 31 points. Hence the capability to measure the changes in organizational function of management is found $9.68 \%$ as shown in Equation 2 .

$$
O F=\left(\frac{3}{31}\right)=9.68 \%
$$

Since it is a low score, in order to meet the requirements of the competitive market structure, it must employ some more organizational structures. At least, a structure of focusing on customer demands, for instance, establishing customer representatives for important customers will definitely increase the market share. Moreover, some units can be transferred to 
different locations, for example, a nearby area to suppliers or customers, indicating a territorial structure, can aid the company to decrease the costs.

\subsection{Innovation in Leading Function}

When the leading function is analyzed, "Dictative", "Hierarchical", "Participatory", and "Esteemed" behavior styles are observed. However, the leader is not in a supportive manner, since he only listens to his subordinates but none of them can take a role in the decision making process. Depending on these 4 behavioral styles, the company gathers 27 points from the maximum available of 31 and resulting $87.1 \%$ success to follow the changes in leading function of management as shown in Equation 3.

$$
L F=\left(\frac{27}{31}\right)=87.10 \%
$$

Although the leader seems to follow the requirements of modern age, an unsupportive behavioral style de-motivates the sub ordinates and workers, which is observed through the expert survey performed with them. Hence it is better to bring out a new system that rewards the workers if their ideas succeed in any operation, which can be a good indicator of a supportive style and definitely increase the worker motivation.

\subsection{Innovation in Controlling Function}

The company makes the controlling activities any time when it is required as well as on a timely schedule defining the period and frequency of each control, indicating a "Scheduled" controlling system. Moreover, the product variety changes over time and their controlling mechanism is ready to be adapted to new items, representing a "Flexible" technique. Furthermore, every worker is responsible of their work and controls permanently, an evidence of a "Continuous \& Self" controlling method. However, it is hard to mention about an aggregated controlling tool, such as a computerized system enabling the controlling of each department by the management. Based on these 4 controlling tools, the company gathers 15 points over a maximum of 31 and the degree of following the changes in controlling function is calculated \%48.39 as shown in Equation 4.

$$
C F=\left(\frac{15}{31}\right)=48.39 \%
$$

Since, one of the most efficient controlling techniques is not used; this degree is less than $50 \%$. By applying an aggregated controlling system, enabling to perform all control actions at one hand, it will be helpful to analyze activities whether they meet the company objectives or not. 


\subsection{Innovation in Coordinating Function}

Each individual worker can contact with the general manager in case of a need representing a "Direct" communication channel. In addition, the general manager frequently communicates with the department leaders and they inform the workers, indicating a "Hierarchical" approach. As an evidence of "MIS" application, based on their Management Information System, all employees from all levels can contact each other and coordinates the tasks. On the other side, although they use internet technologies, there is not a direct link between the suppliers or the customers through a system. Furthermore, it is hard to mention about an AI based coordination technique at all. Hence, by implementing the mentioned three coordinating techniques, the company aggregates 1,2 and 4 points, resulting of 7 points from the available maximum of 31 , and the degree of following the change in coordinating function becomes $22.58 \%$ as shown in Equation 5.

$$
\operatorname{CoorF}=\left(\frac{7}{31}\right)=22.58 \%
$$

In order to increase this low level score, the usage of internet applications must be disseminate to the suppliers and customers by integrating them to the MIS program used within the company. In addition, an AI based system, which can autonomously detect the low level of raw material and enabling to contact to the supplier and inform, will definitely minimize the risk of out-of-stock situations.

\subsection{Degree of Managerial Innovation}

Depending on the analysis of 5 managerial functions, according to the methods performed for each of them, the capability to keep up the changes occurring in each function is calculated separately. In order to aggregate these capabilities to calculate the degree of managerial change, the relative importance of these functions is surveyed through a questionnaire sent both to academic and industrial experts in the subject. Based on the 385 replies of 748 surveys, the relative weights are computed and listed in Table 2 as well as reviewing the capabilities to follow the changes for each function.

\begin{tabular}{|l|c|c|}
\hline \multicolumn{1}{|c|}{ Management Functions } & Capabilities & Weights \\
\hline Planning & $35.48 \%$ & $35.48 \%$ \\
\hline Organizing & $9.68 \%$ & $9.68 \%$ \\
\hline Leading & $87.10 \%$ & $87.10 \%$ \\
\hline Controlling & $48.39 \%$ & $48.39 \%$ \\
\hline Coordinating & $22.58 \%$ & $22.58 \%$ \\
\hline Degree of Managerial Innovation & $\mathbf{4 3 . 2 3 \%}$ & \\
\hline
\end{tabular}

Table 2. Capabilities to follow the innovation in each function and their relative weights 
Both the capabilities to follow the changes for each function and the relative weights are aggregated to find out the degree of managerial change, which is calculated by following Equation 6 and found as $43.23 \%$.

$$
\delta M I=\frac{\left(W_{P} * P F\right)+\left(W_{O} * O F\right)+\left(W_{L} * L F\right)+\left(W_{c} * C F\right)+\left(W_{C o o r} * \operatorname{Coor} F\right)}{W_{P}+W_{O}+W_{L}+W_{C}+W_{\text {Coor }}}
$$

SMI: Degree of Managerial Innovation

$W_{p}: \quad$ Weight of Planning Function

$W_{0}: \quad$ Weight of Organizing Function

$\mathrm{W}_{\mathrm{L}}: \quad$ Weight of Leading Function

$W_{c}: \quad$ Weight of Controlling Function

$\mathrm{W}_{\text {Coor }}$ : Weight of Coordinating Function
PF: Innovation in Planning Function

OF: Innovation in Organizing Function

LF: $\quad$ Innovation in Leading Function

CF: Innovation in Controlling Function

CoorF: Innovation in Coordinating Function

\section{Results \& Discussion}

The proposed model is employed on a manufacturing company to investigate the degree of managerial innovation. According to the survey with the general manager and the analysis performed with the employees, the techniques which are used, is determined and shown in Table 3.

\begin{tabular}{|l|c|c|c|c|c|}
\hline $\begin{array}{c}\text { Manufacturing } \\
\text { Management } \\
\text { Types }\end{array}$ & Planning & Organizing & Leading & Controlling & Coordinating \\
\hline $\begin{array}{l}\text { Pre-Scientific } \\
\text { Management }\end{array}$ & Rules & Product & Dictative & If Required & Direct \\
\hline $\begin{array}{l}\text { Departmental } \\
\text { Management }\end{array}$ & Procedures & Departmental & Hierarchical & Scheduled & Hierarchical \\
\hline $\begin{array}{l}\text { Process } \\
\text { Management }\end{array}$ & Planned & $(2)$ & $(1)$ & $(2)$ & $(2)$ \\
\hline $\begin{array}{l}\text { Management } \\
\text { By Objectives }\end{array}$ & Programs & Customer & Participatory & Continuous \& Self & Internet \\
\hline $\begin{array}{l}\text { Virtual } \\
\text { Management }\end{array}$ & Rolling Plans (16) & $(8)$ & $(8)$ & $(8)$ & MIS \\
\hline
\end{tabular}

Table 3. Techniques used for Management Functions 
By aggregating the scores of each function with their relative weights, which are gathered through a survey, degree of managerial innovation is calculated as $43.23 \%$ by Equation 6 . Hence it can be called as unsuccessful to follow the changes in managerial functions. Since, to adapt to new techniques at least the manufacturing company should have a degree of greater than $50 \%$. Otherwise, it is inevitable to lag behind the new technologies and developments, and in the future it is a great risk of losing the market share in the industry. Hence some enhancements are suggested to the company to overcome this issue.

- For the planning function, the rolling plans are the most contemporary ones to adapt to the changes in manufacturing systems and should be embraced to planning function.

- For the organizational structure, it is better to organize with some territorial units, regarding the customer demands, with a process management perspective.

- For the leadership behavior, to motivate the workers with a rewarding system should be brought up for the successful ideas of the workers, to be in a supportive style.

- By implementing an aggregated controlling system, inspection of the manufacturing system can be supervised wisely.

- It is definite that by coordination of the suppliers and customers in a unified computer system, time losses and labor failures can be prevented by autonomous order releases aided by an Artificial Intelligence system.

\section{Conclusion}

Although the management science and change management are both widely researched in the literature, the novelty of this study is to release a new approach to measure the degree of managerial innovation, which is never before studied. Since the change management is one of the hottest subjects of the time being, the evolution of management science is investigated at first. Depending on this analysis, the techniques used for 5 managerial functions and their evolution by the time are elucidated. Based on this progress, a model is proposed to analyze the capability to follow the changes occurring in the techniques implemented for the management functions. According to this model, the primitive techniques take the least scores whereas, the most contemporary ones take the highest score, since they are capable to meet the post modern requirements. By a case study of this model for a manufacturing system to find out the capability of following the managerial innovation, enhancements are suggested to the company for each management function.

By the definition of change, the techniques used for the management functions are never constant and should be ready for the change due to technological developments. Hence this 
model should be viewed perpetually for the addition of new methods or replacing the prior ones. Moreover, the manufacturing companies are better to check the existence of better and more contemporary techniques, which are proper for their organizational structure and objectives. Hence this analysis should not be performed for only once at a time, but periodically reviewed regarding the changes.

Depending on the requirement of a perpetual managerial innovation analysis, it can be handled easily by implementing an intelligent agent based control system. By the help of this system, it is straightforward to check the degree of capability to follow the changes occur in the techniques of managerial functions, constantly. The design of such a system can be the topic of another study based on this approach.

\section{References}

Armenakis, A.A., \& Bedeian, A.G. (1999). Organizational Change: A review of theory and research in the 1990s. Journal of Management, 25(3), 293-315. http://dx.doi.org/10.1177/014920639902500303

Benner, M.J., \& Tushman, M.L. (2003). Exploitation, Exploration, and Process Management: The Productivity Dilemma Revisited. Academy of Management Review, 28(2), 238-256.

Birkinshaw, J., Hamel, G., \& Mol, M. (2008). Management Innovation. Academy of Management Review, 33(4), 825-845. http://dx.doi.org/10.5465/AMR.2008.34421969

By, R.T. (2005). Organizational Change Management: A critical review. Journal of Change Management, 5(4), 369-380. http://dx.doi.org/10.1080/14697010500359250

By, R.T., Burnes, B., \& Oswick, C. (2011). Change Management: The road ahead. Journal of Change Management, 11(1), 1-6. http://dx.doi.org/10.1080/14697017.2011.548936

Chase, R.B., \& Prentis, E.L. (1987). Operations Management: A field rediscovered. Journal of Management, 13(2), 351-366. http://dx.doi.org/10.1177/014920638701300210

Cole, G.A., \& Kelly, P. (2011). Management Theory \& Practice. 7th Edition. UK: South Western Cengage Learning.

Daft, R.L. (2008). New Era of Management. 2nd Edition. Ohio, USA: Thomson Southwestern Press.

Drucker, P.F. (1993). Management: Tasks, Responsibilities, Practices. NY, USA: Harper Collins Publisher.

Drucker, P.F. (2007). The Practice of Management. Oxford, UK: Drucker Collection Edition, Elsevier. 
Ford, R.C., \& Randolph, W.A. (1992). Cross functional structures: A review and integration of matrix organization and project management. Journal of Management, 18(2), 267-294. http://dx.doi.org/10.1177/014920639201800204

Gomez-Mejia, L.R., \& Balkin, D. (2011). Management. 1st Edition. USA: Prentice Hall.

Griffin, R.W. (2010). Management, 10th Edition. OH, USA: Southwestern Cengage Learning Publishing.

Hitt, M.A., Black, S., \& Porter, L.W. (2011). Management,. 3rd Edition. USA: Prentice Hall.

Gupta, C.B. (1992). Contemporary Management. New Delhi, India: Ashish Publishing House.

Introna, L.D., \& Petrakaki, D. (2007). Defining the Virtual Organization. In S. Barnes (Ed.). ECommerce and V-Business Digital Enterprise in the 21st century. 2nd Edition. NY, USA: Elsevier, 181-200.

Johnson, J.A., \& Breckon, D.J. (2006). Managing Health Education and Promotion Programs Leadership Skills for 21st Century. 2nd Edition. USA: Jones and Bartlett's Publishers.

Jones, G.R., \& George, J.M. (2010). Contemporary Management. 7th Edition. USA: McGraw Hill/Irwin.

Mol, M.J., \& Birkinshaw, J. (2009). The Sources of Management Innovation: When firms introduce new management practices. Journal of Business Research, 62, 1269-1280. http://dx.doi.org/10.1016/j.jbusres.2009.01.001

Murray, A. (2010). The Wall Street Journal Essential Guide to Management. 1st Edition. NY, USA: HarperCollins.

Robbins, S.P., \& Coulter, M.K. (2009). Management, 10th Edition. USA: Prentice Hall.

Robbins, S.P., De Cenzo, D.A., \& Coulter, M. (2010). Fundamentals of Management. 7th Edition. USA: Prentice Hall.

Roth, W. (1994). The Evolution of Management Theory: Past, Present, Future. Florida, USA: St. Lucie Press.

Smit, P.J., Cronje, G.J., Brevis, T., \& Vrba, M.J. (2007). Management Principles, A Contemporary Edition for Africa. 4th edition. Cape Town, South Africa: Juta \& Co.

Taylor, F.W. (2007). Shop Management. USA: BiblioBazaar Publishing.

Taylor, F.W. (2010). The Principles of Scientific Management. NY, USA: Cosimo Publishing.

Thomson, V. (1995). Process Management in Manufacturing. Control Engineering Practice, 3(4), 537-543. http://dx.doi.org/10.1016/0967-0661(95)00026-Q 
Wallman, J.P. (2010). Strategic transactions and managing the future: a Druckerian perspective. Management Decision, 48(4), 485-499. http://dx.doi.org/10.1108/00251741011041300

Witzel, M. (2004). Management, the Basics. NY, USA: Routledge Taylor \& Francis Group.

Witzel, M. (2005). The Encyclopedia of the History of American Management. Bristol, UK: Thoemmes.

Wren, D.A., \& Bedeian, A.G. (2009). The Evolution of Management Thought. 6th Edition. USA: John Wiley \& Sons.

Journal of Industrial Engineering and Management, 2014 (www.jiem.org)

Article's contents are provided on a Attribution-Non Commercial 3.0 Creative commons license. Readers are allowed to copy, distribute and communicate article's contents, provided the author's and Journal of Industrial Engineering and Management's names are included. It must not be used for commercial purposes. To see the complete license contents, please visit http://creativecommons.org/licenses/by-nc/3.0/. 